\title{
ENADE-2001: ¿Un compromiso de todos?
}

Francisco Javier lbisate

\section{Lo mismo, pero diferente}

Con un mes de intervalo hemos conocido dos anailisis de la realidad nacional: EI Informe sohre Desarrollo Ilumano-2()()I y I:NADI:-2()() I. I:I objelo del análisis es el mismo: Ei Salvador y su realidad nacional. pero el enlocue y las molivaciones son diferentes. Ambos anilisis han tenido como préímbulo los litulares de los diarios a linal del primer semestre: "Recaícla economica. I:conomía aún no se recupera. La siluación es preocupante. I a agonía del calic. Iicconomías al viento", en referencia a la recesion mundial.

Siendo grupos de autores diferentes y siendo, sin ducla, las molivaciones diferentes, lambién serán diferentes los enfoques de estos anilisis. Uno habla de crecimiento y creación de riquezal para reducir la pobreza; lil otro se ecintra en el desarrollo humano y parece decirnos que la pobreza crece con el crecimiento económico, antes y después de los terremotos. Hi uno es mís local: "Todos por la reaclivación de El Salvador"; el otro nos uhica comparativamente en el mundo actual. El uno habla de un "nuevo" El Salvador; el otro describe cómo estí el actual. El uno pide "el compromiso de lodos"; el otro invita a "la preocupación de Iodos". El uno hace el pancgírico del mercado; el otro traduce en cilras sus consecuencias. El uno es la aclualización de ENADE-2()(o), el otro es la secuencia de informes auspiciados por Naciones Unidas. En consecuencia, el uno es más empresarial, con más detalladas medidas y más reclamos al fistado; el otro es más estructural con algunas recomendaciones generales.

Siendo diferentes análisis sobre la misma realidad pueden ayudarnos en el caminar hacia un "plan de nación", movimiento que se viene impulsando en los últimos años desde distintos grupos sociales y académicos. Ile acjui una breve

ENADE-2001: ¿Un compromiso de todos? 
III' IIII) lia. ( 'uando nuestra economía se hallaba en patente declive, el presidente 1 ilikelill Sol (en sus discursos de $1^{\circ}$ de mayo y $1^{\circ}$ de junio de 1907) juzgó que 'ra previso encomendar a un grupo de personalidades distinguidas la prepara‘ın de un Plan Nacional de Desarrollo, "con una visión de mediano-largo pla(1), (que nos lleve al desarrollo y genere estabilidad y confianza. Necesitamos lener una visión de largo plazo para dar estabilidad y continuidad al país, más alli de los períodos de gobierno, a lin de convertir a nuestro país en un lugar alractivo para la inversión y generación de empleo, que eleven el bienestar y calidad de vida de la población".

El modelo no había funcionado y era necesario el flotador de un plan de nación, que el gobierno no diseñó. (Otros grupos e instiluciones, a tralvés de consulta popular y con apoyo de académicos, editaron una secuencia de programas económicos: Bases para un Plan de Nacion; Temas clave's para un I'lan de' Nación; Crecimiento estéril o desarrollo; Crecimicento con participacion; I:stado de la Nación en Desarrollo Humano, actualizado en el actual informe de 2001: Plan territorial de la noción. ('uando nos hallábamos en pleno silencio económico gubernamental, ENADF, (julio de 20(0)), intenta sacudir la inercia estatal con su propuesta de reactivación de la economía nacional. 1:1 gobierno dio muestras de prestarle una transitoria alención y el director ejecutivo de la ANEP afirma que se han cumplido un $50 \%$ de aquellas propuestas.

Si bien es cierto que ENADE:-20(0) liene como antecedentes propios los terremotos, la sequía, el calcé y la recesión mundial, los informes antes mencionados señalan fallas estructurales persistentes, que aparecen -al menos entre líneas- en ENADE:-20()1. Su convocatoria rezuma angustia y precocupación. E: presidente de ANEP, Ricardo Simán, vino a decir que "si no enfrentamos adecuadamente estas adversas condiciones, mayores son las amenazals al sistema de libertades que gozamos y al funcionamiento del mercado, ante propuestas populistas o de corte intervencionista estatal, que restan espacio y libertad al accionar privado. Esto no se puede permitir, ya que luchamos por muchos anos para lograr este sistema de liberlades, que debemos continuar mejorando porcue nos brinda el ambiente apropiado para desplegar el ingenio crealivo y la capacidad productiva empresarial y laboral, que deben unirse y aprovechar las oportunidades de un mercado libre, sin distorsiones y en sana compelencia”.

Los titulares de los dias 20) y 30 de agosto traducen la angustia con cierta dosis de agresividad: "Buscamos resullados concrelos. Se refunieren compromi-

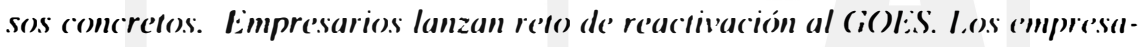
rios quieren respuestas... (iohierno analizará propuestas"... El acuerdo implicito se hace explícilo. "ENADE, como si mismo, es un mecanismo unico; no conozeo yo antecedentes en donde la empresa privada, en vez de plantear sus demandas de tipo sectorial, se crezca a una visión nacional y buscjue la integración de todas las fuerzas políticas y los funcionarios de Gobicrno para construir 
una conciencia nacional en el luluro (lel pais. I:NAI)I: como insirumento es único", dijo el Señor Presidente. Y agrego: "Si para los empresarios y paral el Gobicrno lo más imporlanle es el pais, signilical (jue Irabajamos para loclos los salvaldoreños y trabajamos principalmente para los mís pobres; porcue estamos

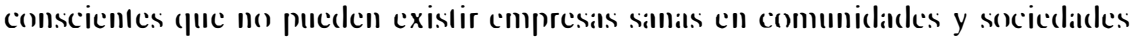
enlermas". I: s Señor Presidente se conliesa hombre de derecha y exalla cl sistema de libre empresal: Lals reglas del juego son ecomomia de mercaldo abierla a la globalizacion.

I:n el discurso de la $\Lambda$ NI:P y en la complacienle respuesia presidencial hay

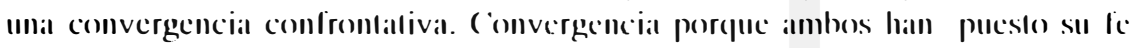
en la economia de libre mercatedo; el modelo no se discule, ni se disculen las consecuencias sociales del modelo. I a divergencia o confromlacion se centran en (jue el gobierno no colaboral sulicientemente paral (fue juegue la libre compelen cial y la lransparencia de un libre mercaldo. I:l gohierno hal permilido (fue surjan luerzass dominamles (fuc impielen la compelencial lolal y al)solulat, al mismo liem po (jue existe pocal informacien alcereal de conlrallos del listado y empresils privi

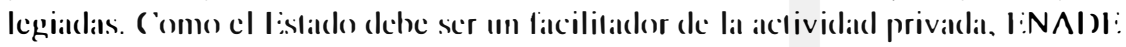

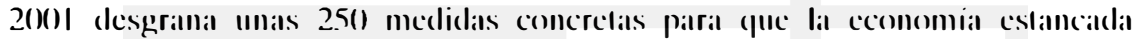
recobre los éxilos y acdivismo propios del modelo. Si la pobrezal existe es por-

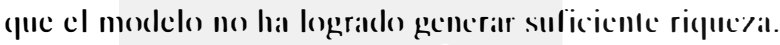

Si el Lisiado no responde a estas demandas podemos volver al "populismo".

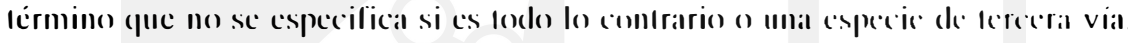
I

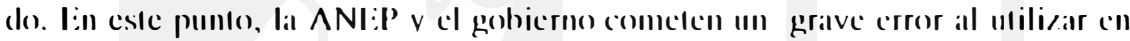
forma despectiva el lermino populismo para (puicones presentan olras allemallivals

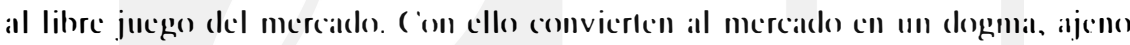
a loda crilica, a comenzar por cuicones lo latchan de "impopular". (onsciente a inconscientemente se distancian de olrals propuestas populares y atcalcmicals y se resisten a reflexionar sobre las consecuencias del modelo. Ioss cosas llaman la

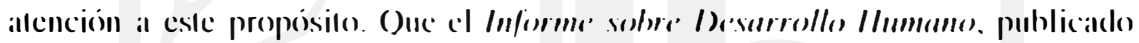

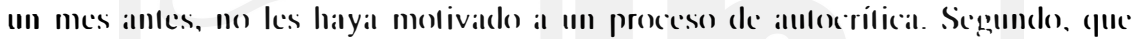
haciendo repelidas referenciass a la globalizacion, no hayann seguido mils de cereal las crilicals de lanlos antores y mamilestamles pacilicoss contral los celectos anlisociales de esla mundializacion. Por supuesto (fuc en los anilisis sociale's y sectoriales, así como en las medielas propuestas, hay aporles valiosos, pero la posicion callegorica de sus principios docerinarios contorpecen el "compromiso de lodos" y la credibilidald en la simbiosis ANI:P-(;) () :S, (juc puede llevalr a mis

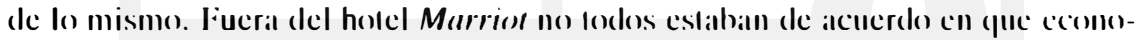
mía de mercaldo, libre compelencia, globalización..., sean simonimos de hienceslar social para amplios grupos no invilados a esia prescentacion.

ENADE-2001: ¿Un compromiso de todos? 
I'n In Imısmu lecha 29 de agosto, el Movimiento Nacional Pro Defensa Del l'urhlu, cinile un manifiesto: "Nosotros, los abajo firmantes, representantes de lifercntes sectores de la vida nacional, profundamente preocupados por la grave crisis económica, política y social que vive nuestro país, producto de la degradación de la calidad de vida, la pobreza, la marginación y la exclusión en la productividad; y ante la permanente violación de los Derechos Humanos individuales y colectivos, el pasado 22 de agosto de 2001 , bajo el nombre de Movimiento Nacional Pro Defensa Del Pueblo nos constituimos como una entidad autónoma, no político-partidista, sin fines de lucro y sin tendencia religiosa, para decir un "Basta ya a la injusticia en El Salvador".

"Por consiguiente, ante el pueblo salvadoreño denunciamos:

"1.- El fracaso del modelo económico neoliberal en todos sus órdenes y las políticas de ajuste estruclural impuestas por Banco Mundial, FMI y BID, (privatizaciones y dolarización) que sólo han traído desempleo, pobrezil, la venta del patrimonio nacional y el ahogamiento de los sectores productivos nacionales, excluyendo y marginando a la sociedad salvadoreña de loda posibilidad de desarrollo. 2.- Que el pucblo salvadoreño no se siente representado por la clase política, ya que sólo se han servido ellos y el sector linanciero y especulativo y las Iransnacionales, creando anarquía y lalla de democracia que no permite que los salvadoreños nos sintamos interpretados directamente para la delensa de nuestros derechos e intereses"... (La Prensa Gráfica, 20) de sepliembre de 2001, p. 43) El manifiesto agrega dos denuncias y seis propuestas. [:NADE2001 no se ganaba el compromiso de lodos.

Como este manifiesto pudiera ser calificado de "populismo" vale la pena agregar unas líneas de un arlículo, escrito en el mes de abril, por el Dr. Álvaro Magaña, ex - Presidente Constitucional, doctor en derecho y graduado de ('hicago: La política económica de los noventa: necesidad de su revision. " $\wedge \mathrm{l}$ inicio de la décala de los noventa, los acuerdos de paz, además de no contemplar ningún aspecio de los problemas económicos y sociales, dejaron una secuela de efectos para la sociedad que no deberíamos olvidar. Así comenzó la que nosotros llamamos la década perdida del neoliberalismo, cuando se inician las políticas que, para la globalización, exigían el Fondo Monetario Internacional y el Banco Mundial, el binomio que nos ha hecho mucho daño. Esstas polílicas tuvieron un alto precio para el país, que los obedientes líderes de la derecha, ya en el poder, aceptaron y hasta ayudaron a conseguir. Pero ya es hora de revisar esa polílica. Comenzaron bajando los impuestos de importación para abrir el mercado salvaldoreño a bienes extranjeros y redujeron la lassa marginal más alla del impuesto sobre la renta al 25\%, o sea, un poco más del tercio de lo que era. De igual modo, se suprimió el impuesto sobre el paltrimonio, el de sucesiones y el impuesto de donaciones, y se descansa exclusivamente en un tributo sobre el consumo que, en su versión moderna, se llama impuesto sohre cl valor agregado 
(IVA). Este impuesto encarece muchos productos necesarios y es hásicamente regresivo".

"Es alentador que despućs de los disturbios de Seattle, durante las reuniones del Banco Mundial y Fondo Monetario Internacional, scguida por los incidentes de Washington y Davos, hasta los más recientes de Porto Alegre (Brasil), ha empezado a tomar fuerza una actitud crítica a la forma de la globalización adoptada por las grandes potencias, que dejan consumirse a los sectores menos privilegiados, no por la pobreza, sino por la miscria, que ahora prima en huena parte del plancta. En el caso triste de nuestro pais, honradamente no podemos decidir quién nos ha hecho más daño, si el hinomio FMI-IBanco Mundial, o los dos primeros gobiernos de la década de los noventa o los dos terremotos del 20()$)^{\prime \prime}$.

El Dr. Álvaro Magaña critica variass vecess el processo de las privalizaciones, "que son el trabajo y el esfuerzo de muchos años..., pues para el aumento de esals inversiones direclas ayuda más el grado de corrupción de nuestros funcionarios públicos y de las entidades autónomas que intervienen en el proceso".

También fustiga la dolarización, "con el apodo de integración monetaria..., todo en cruda violación del Articulo 111 de la Constitución": "Pero hasta donde se supo, no hubo ningún intento por corregir las medidas que dieron algunos resultados positivos, pero que incidieron negalivamente en la economía, aumentando el desempleo y la pobreza, además de otros efectos, que han contribuido al malestar general del pucblo contra los responsables... Aqui esta la triste historia de diez. años desperdiciados, en los que no se hizo nada por el bienestar del pucblo que vio aumentar dramáticamente su miseria, tal como lo muestran las impresionantes cifras de esta década. Issto ocurría cuando gohernó o más bien mal gobernó o desgobernó lo más representativo de la derecha salvaldoreña. Oue no se vaya a salir alguien con que ya no hay que hablar ni de derechas, ni de izquierdas, porque estoy de acuerdo con (iünter (irass cuando hace unos cinco años, en la Universidad (omplutense de Madricl, decía que las ideologías no han muerlo. Mientrass exista miseria, habri molivo para estar a la izcpuierda". (l:c^ $20(0)$; pp. $672-68.5)$

Pocas personas se sentirán honradamente autorizadas para calificar de "populismo" esste arliculo (lel Dr. Álvaro Magaña que da sentido al cilado maniliesto popular. Es normal que, tanto descle las asociaciones laborales como desde al ámbito académico, no lodos se sientan identificados con los principios doctrinarios de [ENADE:-20()1. La alención y el debate se centrarán en el ordenamiento y factibilidad de las medidas propuestas, donde juegan los grupos de presión sobre el Esiado, cuya presencia activa reconoce la misma ANI:P. No podemos extendernos en el eomentario de cala uno de los grupos de polílicas propuestas, admitiendo que el énlasis en las politicass sociales es importante, porque el modo y las prioridades de realización vienen determinados por los

ENADE-2001: ¿Un compromiso de todos? 


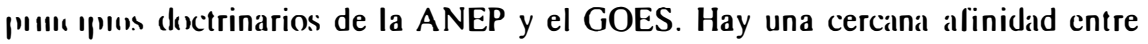
islens principios doctrinarios y los que informan la aclual globalización neoliberal, " la que quiere abrirse el modelo. Luego de dos o tres décadas de globalización. este proceso se ve sometido a fuertes crílicas en países desarrollados y en vías de desarrollo, así como por los manifestantes pacíficos que acompañan las cumbres mundiales. Sin negar los aportes positivos, el debate mundial se centra en las consecuencias económicas, polílicas, sociales y espiriluales de esos principios doctrinarios. Sin embargo, la ANEP reconfirma su fe en los principios de la economía de libre mercado, lo que generará más bien antagonismo que compromiso de todos. Iniciamos la reflexión sobre estos principios.

\section{Marco filosófico-doctrinario}

De julio de $20(0)$ a agosto de $20(0)$ han cambiado bastantes cosas, pero la ANEP permanece fiel a sus principios doctrinarios, lamentando que surjan irregularidades al margen de las mismas normas del modelo. "El aclual sistema económico del país se fundamenta en los principios filosófico-doctrinarios de la economía de mercado. Las hases de este modelo fueron trazadas hace más de una década y, con el tiempo, han tendido a estructurarse a través de un proceso de desregulación, privatización y eliminación de controles de parte del Estado, apoyados en un proceso de apertura frente al exterior. Esto significa que el sistema económico funciona con un alto grado de libertad en donde el mecanismo de los precios y la soberanía del consumidor promueven la compelencia entre los distintos agentes económicos que participan en el mercado. Por definición, esto también significa la eliminación de la intervención arbitraria del Estado en las decisiones de inversión de los mismos agentes". (p. l())

Como a continuación la ANEP afirma que estos principios no han jugado con toda limpieza y surgen otras irregularidades, interesa conocer cuáles son esos principios que generan otros dañinos contraprincipios. En la introducción del Plan de Desarrollo Económico y Social, 1989-1994, se decía: "Una sociedad que quicre ser libre en el plan económico, político y en el orden de los valores y costumbres debe apoyarse en los siguientes principios: 1) El hombre es el lin de la sociedad...2) La libertad es la hase del progreso humano....3) La igualdad ante la ley es la garantía de la paz social...4) La justicia garantiza a cada quien lo que le corresponde...5) El Estado desempeña un papel subsidiario". Estos principios filosóficos se asientan en cuatro postulados económicos:

“1) La propiedad privada es condición necesaria para la eficiencia de la producción...2) El mercado libre asegura la mejor asignación de los recursos....3) I a competencia garantiza el funcionamiento del mercado... 4) El Estado tiene un papel subsidiario".

Estos principios doctrinarios estaban literalmente calcados de una publicación de FUSADES: "Hacia una economia de mercado en El Salvador: hases 
para una estrategia de desarrollo económico y social", publicada en mayo de 1989. Conscientemente se estaba firmando la carta de adhesión a los principios de la globalización. Lo que sucedería al interior de nuestra economía sería un reflejo de lo que sucede al interior de la globalización. Es decir, que para entender la suerte de nuestro país es necesario seguir la historia y la crílica de una globalización que es más que un lénómeno económico.

Conviene recordar que estos principios y parámetros se redactan en lo89, año en que se derrumba el muro de Berlín, y que los acuerdos de paz se firman luego de que en diciembre de 199) se había firmado en Minsk el decreto de la extinción de la URSS, del pacto de Varsovia y del bloque económico del I:sie. Ante el derrumbe de un modelo central y estatalmente planilicado se confirma la teoría del libre mercado como la única respuesta histórica viable. Renegar o abandonar los principios del libre mercado sería regresar a un régimen reprobado por la historia. Se olvida así algo tan importante como real: que la historia del siglo XX ha sido también la historia de los "hermanos irreconciliables socialistas". A inicios, a mediados y a finales del siglo XX son muchos los que han repetido: "ni con unos, ni con otros me puedo identificar en teoria". (()ta Sik) Bastantes gobiernos y muchos grupos de poder siguen olvidando esta realidad, estas posturas de húsqueda que, a veces, se llaman l'erceras Vías, mal vistas y criticadas por las "derechas de ambos lados". Se podrá estar de acuerdo o en desacuerdo, pero no se puede ignorar esta realidad, la búsqueda de algo nuevo y distinto.

Volviendo a nuestro tema, LNADL: 2()() I nos ayuda a descubrir la presencia de superpoderes que creeen al margen de los principios de libre mercaldo. Los ejemplos son claros. "Sin embargo, lodavía existen formas de organización que aprovechan su posición dominante en el mercado, según lo ha reconocido el Banco Mundial, y que impiden que el modelo luncione totalmente apegado a los patrones de una competencia tolal y absoluta. En muchos casos esals figuras manejan aclividades e incluso sectores estratégicos que le restan competitividad al país por deliciencias en el marco regulatorio o en decisiones institucionales que favorecen su presencia. En una medida no (lespreciable, a ello se deben los altos costos de producción con que se enfrenta principalmente la industria nacional, lo cual liene efectos en cadena en las restantes actividades productivas y de servicios. Complica la siluación la poca información existente acerca de los contratos entre el Estado y las empresas, principalmente en lo que concierne a Ios servicios privatizados, lo cual, unido a las debilidades institucionales, da lugar al incremento de tarilas más allá de lo que sugieren los estándares internacionales y a las exigencias de nuevas inversiones en los respectivos sectores o aclividades" (p. 10).

En estas afirmaciones hay algo que no encaja. Primero, dicen que el modelo ha tendido a estructurarse a través de un proceso de desregulación, privatización

ENADE-2001: ¿Un compromiso de todos? 
y eliminación de controles de parte del Eslado, y, a renglón seguido, lamentan los elecios perversos de la desregulación, de la privalización y de la eliminación de controles del Estado, inicialmente aprobados por ellos y sancionados legislativamente por los miembros de su partido, pese a las protestas contra las irregularidades (corrupción) y poca transparencia con que se aprobaron estas leyes. No dehicra extrañarle a la ANEP que esio suceda a nivel nacional cuando observamos mayores imperios en el seno de la globalización internacional.

Las multinacionales dominan el mundo de la producción y del comercio internacional, supeditadas a su vez. a los pánicos o vaivenes de los capitales especulativos de corto plazo. Algunas grandes potencias controlan las instituciones internacionales (FMI, BM, ()MC), que a su vez. controlan la suerte de tantos países. Todo esto es un derivado lógico de la praxis del libre mercado y libre competencia, razón por la cual hoy se habla de gohernar la globalización. Siempre emerge una propiedad privada más poderosa que otras propiedades privadas, una competencia más fuerte que otras competencias y una sumatoria de propicdad privada y competencia de mercado superior a los poderes del mismo tstado. Hay gobiernos que privatizan su propia competencia y no pueden controlarla. Todo esto es una regla o una regularidad cuando no existe una autoridad mundial y nacional capaz de regular las irregularidades del mercado. ('uando la ANEP pide un Estado pequeño y fuerte está pidiendo algo difícil porque la lógica del libre mercado ha generado fuerzas más poderosas que muchos tstados.

Esto parece que sucede en las economías desarrolladas de Luropa occidental, de acuerdo a un autor y una obra que se ha convertido en libro de cabecera. Anthony Giddens, en su obra La Tercera Vía, estí rellexionando sobre el significado de la igualdad, Iema defendido por la ANEP. “¿Qué debería entonces entenderse por igualdad". La nueva política deline igualdad como inclusión y la desigualdad como exclusión, aunque estos términos necesitan alguna precisión. Inclusión se refiere en su sentido más amplio a la ciudadanía, a los derechos y deberes civiles y polílicos que todos los miembros de una sociedad deberian tener, no sólo formalmente, sino como una realidad de sus vidas. También se refiere a las oportunidades y a la integración en el espacio publico. En una sociedad en la que el trabajo sigue siendo esencial para la autoestima y el nivel de vida, el acceso al trabajo es un ámbito principal de oportunidades. La educación es otro".

"Dos formas de exclusión se están manifestando especialmente en las sociedades contemporáneas. Una es la exclusión de los que estcín abajo, aislados de la corriente principal de oportunidades que una sociedad ofrece. En la cúspide está la exclusión voluntaria, "la rébelión de las élites": una retirada de las instituciones públicas por parte de los grupos más ricos, que eligen vivir separados del resto de la sociedad. Los grupos privilegiados empiezan a vivir en co- 
munidades fortificadas, y se aparlan de los sislemas públicos de educación y sanidad. Inclusión y exclusión se han convertido en conceptos importantes para analizar y responder a la igualdad...La exclusión en la cúspide no es sólo lan peligrosa para el espacio público, o solidaridad, como la exclusión a la hase: está causalmente vinculada a ella. Oue las dos van juntas se ve fícilmente en los ejemplos más extremos ocurridos en algunos palises como Brasil o Suraifrical. Limilar la exclusión voluntaria de las élites es esencial para crear una sociedad más inclusiva en la base... Finalmente, los países con períodos duraderos de gobierno neoliberal han mostrado mayores aumentos de la desigualdad economica que otros, con Estados Unidos, Nueva Zelanda y Reino Unido a la calleza". (Taurus, pp. 121-127)

Si la $\Lambda$ NEP afirma que hay formas de posición dominante en el mercado, sectores estratégicos que restan competilividad al país y escalsa transparencia en los contratos entre el Estado y las empresals de servicios privalizados (algunas de estos privilegiados estarán adscritos a la $\Lambda$ NEP) lodo esio significa (jue buena parte del sector productivo privado se ubica entre la exclusión de los que están abajo y la "rebelión de las élites", (jue se aparlan de la sociedad y viven en comunidades fortificadas. Iin las sociedades contemporaneas se habrian generado tres capas geológicas: la inferior, la superior y la cue esta encima de la superior. En este escenario se entiende el manifiesto antes citado de los movimientos populares que dieen no estar representados por la clase política. "ya (jue sólo se han servido ellos y el secer financiero especulalivo y las transnacionales"... Tambien la $\Lambda N \&$ P hace referencia a las Iransnacionales y servicios publicos privalizados, dando a entender (jue esals privallizaciones han sido verdaderas desnacionalizaciones. Por ello seria recomendable no seguir demandando nuevas "concesiones" y privalizaciones para evilar (jue el humerain regrese sobre la cabeza de los solicilantes.

\section{Las expectativas de los precios}

El efecto de la dominación de los grandes esiratos dominantes a escala mundial está desnaturalizando el nivel de los precios, muchos de los cuales dejan de ser medida de valor. La ANI:P alirma (jue "el mecanismo de los precios y la soberanía del consumidor promueven la compelencia entre los distintos agentes que participan en el mercado". También estas alirmaciones leóricas han guedado bastante desfiguradas en el entorno de la globalización. A. Ciddens dedical el último capílulo del libro cilado al fundamentalismo de mercado a escala mundial. La Tercera Vía se escribe en 1908, cuando la crisis financiera mundial sobrevuela los mercados de la producción y abale las economias de lanlos paises. A. Giddens resume lo expresido por muchos atulores. "En la orlodoxia neoliberal, dar tolal libertad a los mercados globales es lógico, porque, como todos los mercados, son mecanismos que resuelven los problemas y lienden al equilibrio. Una descripción más conveniente de la dinámica de los mercados

ENADE-2001: ¿Un compromiso de todos? 
mumult.16es sllpere, sin embargo, que son las expectativas de las flucluaciones de lur. prevos, mis que los precios en sí, las que impulsan las decisiones, y las ‘xpeclalivas son habilualmente inducidas, más por lenómenos psicológicos, que por puramente económicos. C'risis, llucluaciones errálicas, la repentinal alluencia de capital que entra y sale de delerminados paises y regiones, esios no son rasgos marginales, sino centrales, de los mercados descontrolados".

Aunque estos párrafos parecen alejarnos de nuesiro pequeiio mercado veremos enseguida que nos iluminan para entender nuestro escenario nacional. $\Lambda$. Giddens sigue comentando: "Aquí, como en todas partes, desregulación no es igual a liberlad, y un compromiso global con el libre comercio depende de la regulación eficaz. en lugar de hacer casso omiso de su necesidad. I os objelivos de tal intervención son fáciles de identilicar, pero qué politicas concrelas debieran seguirse y cómo pueden ser implementadas es obviamente más problemálico. Las necesidades son re: lringir los excesivos movimienlos de los capilales y controlar los excedentes; separar la especulación monelaria a corlo plazo de la inversion; y fundar una mayor responsabilidad entre las organizaciones transnacionales involucradas en la gestión economica mundial, a la vez que reestructurarlas. Del billon de dólares USA en divisas que se inlercambian a diario, sólo .5\% deriva del comercio y olrass Iransalcciones economicass sustantivass. El otro $95 \%$ está compuesto por especulaciones y arbitrajes, al buscar los negociantes, que manejan sumas enormes. heneficios rápides en fluctuaciones de lipo de cambio y diferenciales de lipo de interés. Istas aclividades distorsionan las señales que dan los mercaldos para las operaciones de largo plazo y el comercio". (1P. 17.3-174)

Esta especulación en el mundo internacional nos estí afeclando en forma direcla e indirecla. ANEP y el gohierno nos dieen que la recesión de la economía de los Г: [:UU alecla negalivamente nuestra economía. Ante lal hecho conviene preguntarse por que esal economia, que en el foro de Davos-20)(1) se presenlaba como "la nueva economia" de crecimiento sosienido, ha sulrido lan seria contracción en menos de un año. La explicación la encontramos en la carrera especulativa en holsa de valores. Iin el mismo foro de Davos el enlonces secrelario del Tesoro, Iarry Summers, y el presidente del F:MI, Slanley Fïsher, mosiraron su preocupación por el elevado endeudamiento de lamilias y empresas comprometidas en la deshocada compra de lílulos-valores leconológicos, que en casso de ralentización económica colocaria en dificultades a muchas familias. En éste, que es el mayor mercado del mundo, no fueron los precios, sino las expectativas de los precios de las demandas y oferlas alipicas de bolsa de valores lo que está en el origen de la actual recesión norleamericana. Lester Thurow lo expone brevemente: "Aquellos que invirtieron en infracstruclura de telecomunicaciones se encontraron con que el valor de las acciones subía más que el costo de las inversiones. Iloy día, después de la caicla, el mercado está haciendo exactamente lo contrario. Aquellos que contrajeron grandes deudas estín siendo 
penalizados por esas enormes deudas. Lo que antes se premiaba, ahora se penaliza, y el nivel correcto de inversión está muy por debajo de donde estaba". lin el mismo artículo, Lester Thurow recuerda que la anterior especulación inmobiliaria en Japón Ilevó a la prolongada recesión de su economía y gue lambién Europa está amenazada por la excesiva inversión en infracstructura de lelecomunicaciones. La especulación y sus expectativas de precios no sólo cassligan a la especulación, sino al sector real de la producción.

Especulación inmobiliaria y financiera siguen siendo fuer/as desestabilizadoras de nuestras economias, algo que $\Lambda$ NI:P y FUSAI)LS habían adverlido al hacer el análisis económico de 1994, analizando la canalización del crédilo hancario. He aqui un casso ilustrativo. ('on fecha 22 de septiembre, I.a P'rensa Circifica presenta en litular: Wall Sercerl perdio la batalla, adjunlando un recuadro digno de alenta reflexión: "I'alriotismo y especeulacion". "Al cierre de la sesicin de ayer los operadores del Wall Sirect estallaron en aplausos y vilores. Pese a caue se pensó en algún momento (jue el "paltriotismo" de los inversores lograria salvar la bolsa de la luerle caida, lo cierto es gue el espiritu de sacrilicio de los agentess se limitó a guardar un minulo de silencio, cantar el "(iod Bless America" y pegar banderilas estadounidenses. I.o cierlo es (jue nadic esperaba fule los agentes de Wall Sirece, acostumbrados a especular y buscar las ganancias a loda cosla, deluvieran su aclividad para pensar en el bien de la palria. I a malvoria de los agentes coincidió en (pue lo verdaderamente palricitico era pensar en si mis mos y en sus lamilias. Iis decir. lo (jue hacen siempre... i. ()uicn diablos quicre ponerse en frente de un tren de carga en marcha! Anle la posibilidad de anta guerra las bolsas curopeas caveron, v los inversores compraron francos suigos, oro y bonos de alla calidad credilicia, mic neras el dobar cavo a $111 \mathrm{~m}$ mom!mo en 20 meses frente al franco suigo". (Pp. 30)-31) Se podria agregar un subletulo: Rolso

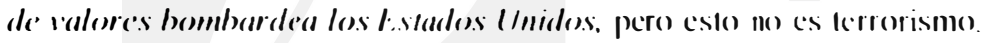

Algo similar sucede en el cenestionado enemercio internacional, donde las expectativas de los precios y no los precios reales determinam lin reliaciones

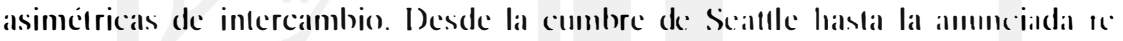
unión de Doha, ()atar, nuestros presidenles y ministros han aprendido (fue las ayudas y subvenciones concedidas a las exporlaciones del Norle se conficontan con los contingentes y harreras arancelarias y sanitarias impuestas a las cxpotaciones del Sur. El presidente Jermando (ardoso lo expresó claramente én la réunion de

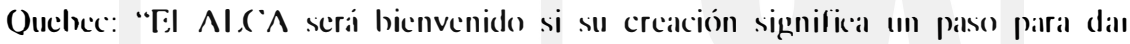
aceeso a los mercados mais dinimicos, si clectivamente significa el camino para las reglas compartidas ambidmmping, si redece las harrerass arancelarias, si covila la distorsión proleccionista de las huenas reglas sanilarias. Pero, si no es ast. scrala

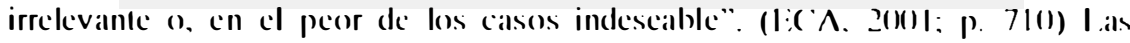
expectalivas de los precios. y no los precios, estin delerminando los valores cíclicos del calcé y del petribleo, gue tanto alecelan a la economia nacional

ENADE-2001: ¿Un compromiso de todos? 
I A IIIsima ANLP denuncia la formación de precios de oligopolios o monopolıus de servicios públicos privatizados. Creer que los precios de mercado derivan hacia un equilibrio que promueve la competencia es válido para algunas compras al por menor, mientras que en los mercados dominantes queda poco espacio para la soberanía del consumidor. La ANEP debe revisar su doctrina sobre el mercado autorregulado, si busca el compromiso de todos. Cuando se decretó la dolarización y empezamos a medir lodos los valores en dólares, encontramos que un salario mínimo de $1.26($ colones equivale a 144 dólares, que es lo que cuesta dormir una noche en uno de los holeles elegantes. ¿La productividad de un mes de trabajo es igual a la productividad de una noche de hotel? Lin otras palabras, ¿la productividad de los salarios mínimos da un pequeño salto sólo cada tres años? ENADE-20(01 debe dialogar sus medidas de polílica laboral, "modernizar el mercado laboral, adaptándolo a un mundo globalizado", para que las remuneraciones salariales respondan a una justicia equitaliva. A linales del siglo XIX, el gran predicador Lacordaire decía en Nôtre Dame de París: "Entre el pobre y el rico, entre el siervo y el señor, entre el débil y el poderoso, la libertad oprime y la ley libera". I.o (jue Lacordaire decía defendiendo a los sindicatos, lo podemos aplicar hoy a las políticas laborales. No deja de Ilamar la atención que en los análisis comparativos de las matrices insumo producto, entre los componentes del valor agregado, se reduce relativamente el poreentaje de remuneraciones de los empleados frente al crecimiento del exeedente de explotación. Esto nos lleval a tocar un punto concomitante.

\section{La soberanía del consumidor}

Otra de las premisas doctrinarias es la soberanía del consumidor, como principio motor del juego del mercado, lo cual se aplicaría directamente al mercado nacional. Se trata del círculo virtuoso donde la oferla crea su propia demanda y la demanda recrea la of erta. Desde esta perspectiva, en el Deparlamento de Economía de la UCA se hizo una tesis titulada: "Nécesidades heisicas y reactivación de la economia". Se trataba de una investigación teririco-príctica. En 1986, el BC.R había publicado la malriz insumo-producto 1978, donde aparecen las interrelaciones de ofertas y demandas de todas las ramas productivas. Se utilizaron los componentes de la canasta básica familiar, partiendo del supuesto que el Estado iniciaba una inversión de $1(0)$ millones de colones, (jue se convertían en los salarios iniciales de trabajadores contratados a tal fin. Combinando los componentes de la canasta básica y los correspondientes sectores productivos, de acuerdo a los datos de la matriz, siguiendo el proceso de demandas y ofertas recíprocas, se llegó a la conclusión de que la canasta básica tenía un efecto multiplicador de 2,72.5. Los $1(0)$ millones de inversión inicial habían generado a lo largo de seis años una producción total de $272,467.774$ colones. con los correspondientes empleos, ingresos laborales y empresariales, así como las necesarias importaciones. Las necesidades básicas podian reactivar la economia nacional. 
La investigación quedó sólo como un ejemplo teórico, porque de 1986 a nuestros días este multiplicador no jugó al alza sino a la haja, en forma contractiva para toda la economía. Como indica el Informe sohre Desarrollo Humano-200), en la década de los noventa hemos conocido un ciclo bifásico de alza ficlicia 1992-1995, seguido de clara desaceleración 1996-2001. Luego de la crisis de gueпа, de 1992 a 1995 se tienen altas lasas de crecimiento, partiendo de una base deprimida y con crecientes remesas familiares. "Sin embargo, sectores que albergan alıos porcentajes de la población, como la pequeña y mediana empresia, el informal y el agropecuario, no se vicron favorecidos con ese crecimicnto. Los salarios mínimos reales tampoco mejoraron con el crecimiento, pese al fuerte retroceso $(50 \%)$ que habían experimentado en la década de los ochenta. Entre 1996 y 2000 , la pobreza conlinuó disminuyendo (igracias a las remesas?') y la coberlura de servicios sociales siguió aumentando. Pero al mismo liempo, el crecimiento entró en una fase de desalceleración, la estabilidad macroeconómica se volvió más frágil, el subempleo se manluvo allo, los salarios mínimos reales se redujeron, los llujos migraltorios de acenluaron y el país se volvió menos competilivo". (p. I) En esos años la economía de Esilados Unidos viajaba viento en popa y los precios del petróleo y del calé no eran lan adversos a nuesira economía.

El Salvador continúa presentando uno de los niveles de desigualdad más altos del mundo. "En 19(9), el 2(1\%, más rico de la población percibió el $56,2 \%$ de los ingresos del país, mientras que el $50 \%$ más pobre sólo recibió un 16,4\%. Para ese mismo año, la razón de los ingresos entre el último quintil (20\% más rico de la población) y el primero (20\% más pobre) fue de 19,4, siendo muy superior al valor registrado en los países de la ()CDE (alrededor de 5) y en los páíses menos desarrollados fuera de América I altina (menos de 7)" (p. 14). Fil 2(1\% del ultimo quintil entiende el lérmino de soberanía del consumidor, lérmino mais bien cabalístico para el resto de la población. I.os representantes de las gremiales de ANLPP debicran haber leído con antelación el informe de desarrollo humano antes de repelir afirmaciones lan conlundentes que no encajan en el marco nacional. Estas deficiencias en las bases doctrinarias restan credibilidad respecto al ordenamiento y prioridad que quicran dar a sus propuestas económicas.

Un poco más adelante el informe del PNUI) resume las consecuencias que estamos viendo y viviendo. "I als altas desigualdades lambién alectan al crecimiento, al reducir las posibilidades de formación de ahorro nacional y estrechar la escala del mercado, impidiendo procesos productivos y teconológicos que permitirian un uso más el iciente de los recursos. Su impacto sobre los sistemas educalives es bastante perverso porque crea circuilos muy diferenciados que, luego, contribuyen a hacer aún más pronunciadas las desigualdades a través de sus repercusiones en las posibilidades de aceeso al mercado y en las remuneraciones del mismo. Por lodo esto, Benabou (1996) sostiene que la desigualdad erosiona la credibilidad en las instituciones y debilita, a través de ello, la

ENADE-2001: ¿Un compromiso de todos? 
pulluruahilidial democrática, además de tener un papel clave en el aumento de lins lensiones sociales"...(p.118)

Como indicara el Dr. Ńlvaro Magaña, ya es hora de que se revisen las medidas económicas a partir de la prolongada desaceleración o recesión con que cierra la década de los noventa. Y ello sin recurrir a la falacia de que dicha recesión se explica por fenómenos externos, como la ralentización de la economía de los EEUU, los precios del petróleo y del café. Antes de estos fenómenos externos y antes de los terremotos la recesión era una consecuencia interna de las fallas del modelo nunca sometido a discusión y evaluación. Sucna a música gastada volver a repetir los mismos estribillos de 1989), cuando una de las principales causales ha sido la alusencia de una soberania del consumidor mayorilario, que puso en movimiento el juego del multiplicador a la baja; cuando se ha ido postergando la elaboración de un Plan de Desarrollo Nacional, disponiendo de una serie de programas que daban los lineamientos, cuando se optó por una apertura externa, descuidando los análisis de las potencialidades presentes en el mercado interno. Es hora de confrontar el dogma con la realidad, si se cjuiere un compromiso de todos.

\section{El mercado interno}

En la segunda parte de I:NADI:-2()()I, "Propmesta politica", calla tema o sector analizado viene precedido de una breve presentación de su estado actual, sus problemas, sus posibilidades, junto con una delallada lista de propuestass. Cada uno de estos prefacios es importante porpue recoge deficiencias o lallas permanentes, como recordar que el sector rural ha sido un espacio marginado, admitir nuestro rezago lecnológico y el divorcio academia-empresal el lasire del delerioro ecológico, la incompelencia instilucional, la inseguridad ciudadana, las deficiencias juridico-legales (icorrupción?) y olras adversidades (jue vienen del exterior. La agresividad es contra estos hechos o contra el Istado, no tanto contra el modelo económico y muy poco contra el propio sector privado. Un enunciado repetido es que el Istado debe ser un facilibdor de la aclividad y creatividad privada, (ue es la principal o cinica creadora de empleo. a través de su trabajo y de sus impuestos. Iil eje del modelo es el mercado. dentro de las exigenciass que impone la glohalización y, en consecuencia, el eje dinamizador será el comercio o mercaldo exterior.: "Alcanzar la mela de exporlaciones para el año $20(1) .5$ de US $\$ 5 .(0)(0)$ millones". ¿Dónde (jueda el mercado interno"

En esta parte se exponen algunas politicas sectoriales, referidas a delerminadas ramas de la economia: agropecuario, micro y mediana empresa, turismo, consirucción, industria, hancos y holsa de valores. Sin negar la importancia de estas propuestas, no deja de extraniar fue los profesionales del mercaldo no hagan referencia - en sus documenlos tradicionales - a la red de mercados internos que interrelacionan a todas las ramas productivas de las fue ellos son parte acliva. ¿Cómo se puede hablar de reaclivación de la economia nacional dejando 
en el olvido el análisis de las posibles fuerzas molrices que subyacen en secelores dinamizantes como olerentes y demandantes de insumos a mayor numero de sectores económicos? Desde 1986, el $B\left({ }^{\prime} R\right.$ ha venido publicando las malrices insumo-producto $1978,190()$ y ha aclualizado las malrices de los villimos anos de la década. La consistencia, armonía y crealividad del mercado nacional se fundamentaría en la consistencia, armonía y crealividad de las relaciones intersectoriales. Ellas nos dan la verdadera eslruclura y crealividad del seceror empresarial. Es un primer significado de lo cue podemos llamar mercado interno. Si falla este mercado, lambién aparecerín las fallas en el mercado final nacional y externo.

Lamentablemente, a lo largo de la década de los noventa se ha ido relegando el análisis del mercado interno estruclural. Para cuedar bien con las medidas y recomendaciones de los organismos internacionales el lijeculivo. y el mismo Banco Central, limitaron su alencion a los equilibrios macrocenomicos de la Contabilidad Nacional, cilras más bien virluales (jue reales. (omo han repelido varios analistas, se lograba el equilibrio de las estadisticas, pero no de la macroeconomía real, que se asienta en una desintegrada, lerciarizada y poco tecnilicada estructura producliva empresarial. Il m ismo l3anco ( 'enlral, aulor de las malrices, las ha silenciado o ignorado en la presentacion de los programas monetarios y linancieros anuales. Tampoco los prolesionales y actores del mercado les han prestado mayor alencion; con cllo, las llamadas politicas seceloriales pueden dar a entender que los sectores economicos son "seclas" separadas unas de otras, y no ramas integradas del mismo irbol economico.

Luego de la firma de los acuerdos de par y cuando en 190$) 3$ el I3( R publical la matriz. 199(), hubo bastante aclividad investigaliva con miras a marcar algunas sendas para el desarrollo economico. Para W. Leonticl, ese cra unos de los lines de las matrices: Orientar el desarrollo economico. (on Irecolencia los paises pobres son pobres, no por falla de recursos, sino por no saber como utilizarlos,

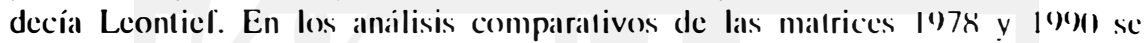
partía del principio que la economía liene un cierlo orden, gue arranca desde los sectores hásicos, avanza hacia los sectores I ransformadores intermedios y desemboca en el mercado final. Así se habían utilizado en la reconsiruccion de otros países destruidos por olras guerras. I $n$ nuestros anilisis comparalivos se apreciaba que un cierto número de seclores y de imporlaciones mostraban mayor capacidad de reaclivación economica. También nos mostrabal, al analizar los componentes del valor agregado, pue la inflacion de una economía de guerra había dehilitado el poder de compra de las remuneraciones de los "empleades", al mismo tiempo que se había elevado porcentualmente el "excedente de explotación de los empleadores", lo cual iba a hacer más dilicil la recuperacion de la economía: la demanda no recrearía la oferla.

Era necesario fortalecer este poder de compra utilizando la capacidad de dinamización de los sectores productivos. $\Lambda$ este fin se listaron las 20 ramas más

ENADE-2001: ¿Un compromiso de todos? 
importantes por sus aportes al Valor Agregado y como oferentes y demandantes de insumos a mayor número de sectores económicos. Si el crédito bancario se canalizara a estos sectores se podía consolidar el tejido productivo de la economía interna y" el poder de compra del mercado interno. La misma ANEP y FUSADES lamentaban, en 1994, que el crédito bancario buscara más hien sus beneficios monelarios que la reactivación de sectores que crean más empleos, ingresos y divisas. Uno de lantos trabajos llevaba por lítulo: "Aportes c'conómicos de las matrices insumo-producto 1978-1990) a los programas de desarrollo 1994-1999". (Realidad, N³9) La aplicación de estas polílicas necesilaba la colaboración de un Estado orientador y propulsor de la reactivación económica, puesto que el Banco Central había sido el autor de este radar económico. Fira de esperar que el sector privado se afiliara a esta misma tarea, dada su crealividad y capacidad de generar nuevos empleos. Una vez más, los aporles de varios institutos de investigación quedaron en el limbo de las bibliotecas.

El esquema de ENADE-2(0)1 se asienta en "un proceso de apertura frente al exterior". En principio estamos de acuerdo en los efectos del multiplicador del comercio exterior; pero ¿cómo se puede afianzar un proceso de aperlura exterior sin fortalecer la estruclura productiva interna?. En 1992 se crea la (omisión de Ciencia y Tecnología (CONAC Y'T) para recordarnos que tenemos un serio rezago tecnológico frente a un mercado mundial ascntado en la revolución tecnológica. Carolina Alas de FUSADES, en su análisis del Nucvo linorno Inernacional de Comercio, nos recuerda que la compelencia y la eficiencia son los parámetros del mercado internacional; si el rezago tecnológico, la deficiente infraestructura y la mala calidad de los servicios públicos hacen difícil la reconversión del aparalo productivo, "la desintegración que puede gencrarse con la apertura rápida de fronteras generará desempleo, con los consiguientes conflicıs sociales". A continuación afirma cue las economías centroamericanas nacieron y se mantuvieron bajo la sombrilla de una fucrte protección arancelaria". (Boletín Económico y social de FUSADES, No 179)-18()) fil recordado investigador, Salvador Osvaldo Bran, escribía en 1997 que, a causa del prolongado proteccionismo, nuestro sector productivo aplicó el principio del menor esfuerzo tecnológico, eludiendo los riesgos asociados a la innovación tecnológica, buscando el crédito preferencial, los subsidios y la publicidad, prácticas que deben erradicarse para ser competitivos. (EC., $1997 ;$ p.546)

Pareciera que ENADE-20()1 comicnza a reconocer algunos de esios defeclos. Al desarrollar las políticas sociales y la competitividad, aplicadas a la educación, se dice: "El Salvador presenta serias limilaciones para enfrentar los retos de la globalización y la revolución mundial del conocimiento, ya que el desarrollo de la ciencia y la tecnología en el país ha sido históricamente escaso y no se observan signos de mejora sustancial. Cambiar esta realidad exige un esfuerzo nacional, en el cual los sectores público y privado reorienten sus inversiones y gestión hacia el desarrollo y la transferencia de tecnología, con el fin de aprove- 
char el conocimiento disponible en el mundo y absorber, dilundir y ulilizar el mismo en aplicaciones que mejoren los procesos produclivos y le den a nuestro país la capacidad necesaria para compelir en los mercados globales. La empresal y la academia deben integrarse en un ambiente de ganar-ganar, en el cual los recursos de la empresa ayuden a generar conocimienlo por parle de la segunda y que éste pueda ser aplicado a la producción de bienes y servicios, relribuya el esfuerzo y genere una espiral de desarrollo y bienestar social" (p.14). "Nosotros hemos ido asumiendo la necesidad de mejorar nuestros procesos de producción. de introducir lecnología, de que nuestros trabajadores se capacilen y con ello mejoren sus salarios reales. Esta es una labor (que vamos a seguir realizando para competir en los mercades globales" (p. II).

Precisamente estos eran algunos de los objelivos que se huscabal lograr con los análisis comparativos de las malrices insumo-produclo, que, entre ol rass cosass, nos dan la estruclura lecnológica de producción de cada rama economica. En esie sentido hay que felicilar a los aclores de la malriz. 1978, presentada con siete sábanas: las fres primeras dan los valores absolulos de las relaciones intersectoriales de nuestras ramas produclivas, distinguiendo insumos nacionales y externos; las tres siguientes ofrecen los coelicientes lécnicos de produccion de las mismas ramas, es decir, la estruclura leconologica de producción; y la séplima ofrecia los coeficientes lécnicos inversos, pue sirven a la planeacion de las allernativas de crecimiento. Por desgracia, el Banco ( éntral al ver (jue este radar economico ha carido en desuso- ha reducido a una simple sabana las recienles matrices de los años noventa. Una de lass modaliclades de aprendizalje leconologico era el análisis de los coeficientes lécnicos de produccion de paises algo mis avanzados que el nuesiro. (ué gran servicio nos harian las gremiale's de la ANEP si, ulilizando su poder de persuasion y sus aporles estadisticos propios, lograran que el Banco (entral y sus calificados lécnicos volvieran a recediar estas malrices en la forma expresada. listo ayudaria mucho a la vinculación de la empresa y academia para avanzar en el deseado desarrollo leconologico. No olvidemos que el mercado interno estai hecho de relaciones intersectoriales.

\section{Políticas sectoriales y territoriales}

Ilablar de politicas sectoriales y lerriloriales es aceplar (jue la palabra mercado es algo abstraclo, y (ue lo (jue existe en realidad son varios mercados y distintas zonas geográlicas dentro de cada nacion. Por lo lanto, que hay que dar coherencia a lo que existe y reponer lo que no exisle. Alguien liene que integrar los sectores para que no se convierlan en sectas desintegradas y alguien liene que promover el desarrollo equilibrado de las regiones. Las armonias y los equilibrios no nacen espontineamente y la compelencia lleva mis bien a la marginación o discriminacion. Iil Salvador ha sido y es hastante desigual en su dimensión lerritorial y en la preeminencia de unos sobre otros seclores produclivos.

ENADE-2001: ¿Un compromiso de todos? 
Un aspecto positivo de ENADE-20() I es la interrelación que presentan las áreas sociales y económicas y hasta cierlo punto entre las ramas productivas, aunque el análisis sigue siendo muy sectorial. Imporlante y positivo que la ANEP resucite el problema de los desequilibrios territoriales, que, sea dicho entre paréntesis ya aparecía en las sábanas de las matrices insumo-producto, y, cerrando el paréntesis, lo han puesto al descubierlo los recientes terremotos y el Informo de Desarrollo Humano 2(0)1. "Aclualmente en el país no existe un plan de ordenamiento y crecimiento territorial, y amplias zonas se encuentran aisladas del resto del territorio a pesar de tener una superlicie apenas superior a los 20 mil kilómetros cuadrados. I o anterior es consecuencia de que las carreteras y vías de comunicación han sido plancadas y desarrolladas a partir de conceptos centralistas, provocando una gran concentración de actividades productivas en las ciudades más importantes y una gran concentración de la pobreza en los lugares más alejados de dichas ciudades" (p. 20). Este párrafo es importante en cuanto recordatorio de un problema descuidado ([:CA, 2()01; pp. 61 I-620), y porque, con el apoyo de la $A$ NEP. puede traducirse en la aplicación de alguna de las medidas concretas propuestas.

Como la Comisión Nacional de Desarrollo habia preparado un plan de desarrollo territorial, que el gobierno adoptó como engendro propio, la $\Lambda$ NI:P lo traduce en un plan de acción: "Dado que las caracteristicas de estas inversiones son de mediano y largo plazo, los recursos necesarios para ejecutar las acciones territoriales demandan voluntad politica y requieren esfuerzos importantes de coordinación entre las diferentes instancias del gobierno central, las municipalidades, las instituciones autónomas, las empresas locales y las distintas organizaciones no gubernamentales que trabajan en el desarrollo local”. (p.20)

Esto plantea un problema de priorización de objetivos y de propuestas concretas. Los objetivos son cinco y es el cuarto objelivo el más relacionado con el desarrollo equilibrado de las regiones: "Apoyar el desarrollo de regiones al interior del pais". Las propuestas son veinte y la más relacionada con este problema es la decimocuarta: "Continuar con el proyecto de Caminos Rurales Sostenibles que permitan el desarrollo de regiones poco comunicadas con el resto del paiss". Entre las primeras propuestas se pide "concesionar" el acropuerto, los ferrocarriles y el puerto de Aciajulla, a la par que se construye el puerto de (uluco. Por supuesto, se agrega la construcción de carreteras y redes eléctricas, el anillo periférico, la villa olímpical, el fondo vial y la referencia al Plan Puchla Panamá. Dadas las restricciones presupuestarias se impone una seria evaluación del costo-beneficio social o "excedente del consumidor" para cada una de las alternativas, entre área urbana y área rural, entre mercado interno y mercado externo.

Si la concentración de las actividades se ubica en las ciudades y la concentración de la pobreza se localiza en los lugares más alejados, el desarrollo ecpuilibrado de las regiones pide que los caminos rurales soslenibles formen parle preferencial de esta agenda y ello por muchas razones. La construcción se haría 
con mano de obra locial, posiblemente desempleadla o subempleadla. I os ingresos de esios Irabajadores se transformarian en demanda de bienes de la cantasta

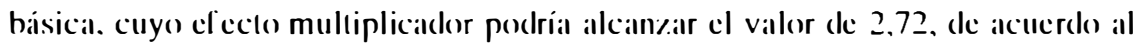
ejercicio antes mencionaldo. Sería muy elevado "el excedente del consumidor", puesto cjue estos caminos rurales permilirian gue los ninos lengan aceseso mais asecpuible a las escuclas, las familias a las uniclades de salud y los pecpueños agricultores podrian acercarse mís a los mercaldos, reduciendo su dependencia de coyoles intermediarios.

I:I desempleo esiructural agrario puede y debe corregirse, entre otras medidas, con la generación de agroindustria localmente ubicalda. Yal se estai hablando de la conveniencia de desarrollar el tostado y fiases finales de embalsado del calei,

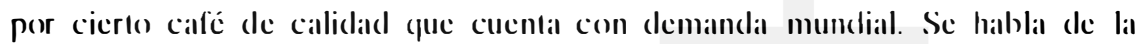
factibilidad de explolación del aniil y del envalsaded de frulas y jalcals, ceramical y olras artesanials. I llegal a la ciudald y no regresal a su punto de origen, la proyectadla red elécirica

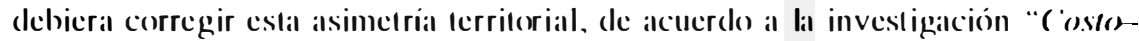
bemeficio ale la clecerificaciom rural", que con linanciamiento del Banco Mundial- se hiciera en la U( $\wedge$ en los anos 70. Si los lerremolos han puesto de maniliesto la marginación rural, el proyeclo de caminos rurales sería un primer peldaño hacia el desarrollo épuilibrado de lass regiones. Indirectamente. este programal serviria a dar mis imporlancia y responsilbiliclad a lass alcaldliass y municipios, reforzando el proceso de descentralizacion y reorganizalción terrilorial. problemas yal analizados en los capilulos segundo y séplimo de "Temas clare's para un plam de neacion". I:l "excedente del consumiclor" sería muy elevido.

Al preferenciar este programa de caminos rurales no estamos segmentando sino forlaleciendo el desarrollo nacional. I:n I:I Salvardor lenemos una deuda con el sector agrario, donde se generaren lass divisals ulilizad lass para linanciar las

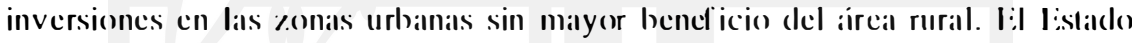
debe recmbolsar esta deuda camalizando la inversión prelerencialmente al seceror rural, como lo estan recomendando lantas instiluciones. Fortalecer el empleo y la demandia del habilante rural beneficiari lambien al mercälo interno urbano. Facilitar la agroindustrial de lanlos derivades agropecolarios puede converlirse en lineias de exportación, en la mediela en cue se logre avanzalr en el proceso de su valor agregado. Por aniadidura, sería una forma de reducir la inmigración urbanal, con sus problemas de desubicalcion personal y hacinamiento lisico. No se debería olvidlar (jue estal mínima "urbanización" (lel campo ayudarial a conservar muchos valores y costumbres tradicionales gue los impactos de la globalización lienden a sofocar. Con fecha 28 sepliembre, los diarios dicen gue no se han logrado los volos suficientes para que la Asimblea aprucbe el prestimo que financiaria los caminos rurales. Por desgracial, el Iriste gremio de los dipulados se desgalsla más en sus ricliculas peleas que en la elaboracicin de un plan de reconsirucción nacional. Triste comporlamicnto.

ENADE-2001: ¿Un compromiso de todos? 


\section{Modernización del Estado}

La mesa quinta de trabajo en Temas claves para un plan de nación se dedicó a "La modernización del Estado". Tema muy dehatido porque se husca una equilibrada conjunción del Estado y del Mercado. Se plantearon tres aproximaciones, destinadas a ser compartidas con los lectores del informe. "a) Sacar al Estado de donde no funciona, para meterlo y fortalecerlo donde sólo él puede velar por los intereses de todos los salvadoreños. Tener una visión sistemática de las instituciones del Estado que permita identificar traslapes de competencias y erradique las zonas grises es una tarea en la que tenemos que trabajar todos los sectores. b) No todo debe dejarse al mercado, debido a que posec, como en todo, imperfecciones. El Estado debe participar como promotor de la competencia propiciando un marco regulatorio apropiado que alcance el objetivo de la eficiencia y eficacia de las instituciones y el mercado. c) Aprovechar la ventaja del mercado, limitando sus características concentradoras, aprovechar las ventajas de la intervención del Estado, sin caer en restricciones intolerables a la libertad social, es un objetivo difícil de lograr pero cuya búsqueda es una obligación" (Pp. 84-85). Este tercer aporte de Héctor Dada marcaba con claridad los problemas de ambos extremos.

"En lo que se refiere a promover una economía de mercado con equidad en nuestro país, los principales componentes de una estrategia orientada a este fin que proponemos son: El Estado como lacilitador del desarrollo económico y social; fortalecer el papel regulador del Essado; asegurar la estabilidad macroeconómica; promover la concerlación social; promover la modernización tributaria; racionalizar el gasto público; promover la transparencia en las contrataciones; garantizar las condiciones de libre compelencia; forlalecer el sistema de prolección al consumidor; impulsar polílicas de descentralización y desconcentración; promover la conservación y recuperación del medio ambiente; y promover la integración centroamericana”. (p. 89)

Consta que al redactor de esta mesa de trabajo le costó integrar los puntos de vista de todos los participantes porque cacla uno echaba un huevo más a la tortilla. Difícil decir si necesitamos un Esiado más grancle o más pequeño; lo cierto es que necesitamos un Estado muy distinto y quizás a esto se le llama modernización. Sería necesario que ese Estado moderno, al servicio de todos los salvadoreños, incluyera algunas otras funciones como la redistribución de posihilidades o de oportunidades, de que habla $\Lambda$. Gicldens, dados los problemas de inclusión - exclusión de nuestras sociedades. Los movimientos populares piden un Estado donde se sientan representados y doncle se controlen las "características concentradoras" del mercado, mencionadas por Héctor Dada.

ENADE-2001 estaría actualizando, descle su visión empresarial, esta alianza de Estado-Mercado: "En la discusión sobre el rol del Eslado, se debale sobre lo que dehería ser su papel y el del mercado en un momento delerminado. Por un 
Estado modemo nos referimos a uno pequeño y fuerte. Debe limitarse el área de acción del Estado a un número reducido de funciones que ni el sector privado ni la sociedad pueden abordar en'forma cfectiva. Sin embargo, no lodo puede de jarse al mercado, debido a que existen imperfecciones; por ello el rol importante del Estado es participar como promolor de la competencia propiciando un marco regulatorio apropiado que alcance el objetivo de la eficiencia y eficacia de las instituciones y el mercado... Para promover una cconomía de mercado con equidad en nuestro país los principales componentes de esta estrategia son: El Estado como facilitador del desarrollo económico y social, fortalecer su papel regulador, promover la modernización tribularia, racionalizar el gasto público, profesionalización del sector público, reformar el sistema de control de la Administración Pública, garantizar las condiciones de libre competencia, impulsar políticas de descentralización y desconcentración, y crear un Sistema Nacional de Estadisticas". (p. 23)

Se percibe una clara afinidad entre los dos últimos párrafos citados de Témas clave's para un plan de nación y ENAI)E-2()()1. Ideologias aparte, Io que aparece claramente es que los tres gobiernos entre 1989 y $2(0) 1$, se han tirado todas estas vallas por el suclo, confirmando la teoría de que los peores enemigos del Estado suelen ser los propios gobiernos, tal como lo expresara el Dr. Nivaro Magaña en su análisis de la década de los noventa.

TI debate se centra en la traducción que demos a cierlas funciones: un Estado facilitador del desarrollo económico y social, su papel regulador, modernización tributaria, imperfecciones del mercado; ¿,Oué se entiende por estas funciones? Sin alargarnos en múltiples comentarios es posible agregar algunos lemas Junto a la creciente corrupción administrativa, que aparece entre líncas en ENADE-2001, se destaca la corrupción de la verdad, el rechazo a toda autocrítica, la distorsión teórica y estadistica de la realidad y de las consecuencias negativas del modelo. Se pudiera agregar la forma inconsulta y poco transparente de la presentación y aprobación legal de la dolarización. También [:NAD):-20(0) silencia que "en un determinado momento", en un escenario de postguerra interna y globalización externa era necesario un Fstado orientador y planilicador, que promoviera la integración de los sectores productivos y de las áreas sociales que aparecen descritas en su informe. Tampoco se integra la necesidad de un Plan de Nación, que hubiera orientado a un mercado privado, que tampoco ha logrado ni crecimiento económico ni desarrollo social. Ten resumen, entre el sector público y el privado, no han logrado una economía de mercado con equidad, mientras que la concentración de la riqueza ha sido el resultado patente.

Conviene contemplar esta realidad desde una perspectiva mundial. $\mathrm{Al}$ presentar la modernización del Fstado FNAD)E-2()()l dice. "(onsideramos esencial impulsar a corto plazo las reformas institucionales tendientes a crear un Estado moderno y eficiente para enfirentar el nuevo entorno internacional, caracterizado

ENADE-2001: ¿Un compromiso de todos? 
por importantes cambios económicos y tecnológicos". Esta visión del entomo internacional :es empresarial por cuanto subraya la primacía del conocimiento científico y su revolución tecnológica como un "proceso de destrucción creativa", admitiendo nuestro descuido y rezago tecnológico. Pero se silencia un aspecto fundamental: que ni el mercado nacional ni la globalización mundial nos han llevado a una economía equitativa, ni a la soberanía del consumidor. El mismo A. Giddens acaba de publicar una corta obra titulada: "Un mundo deshocado. Los efectos de la globalización en nuestras vidas". (Taurus, 200(0) El problema es mundial y objeto de preocupación mundial.

Recogiendo unos breves testimonios, en la cumbre del Milenio, llevada a cabo en Nueva York, en septiembre de 20(0), Koffi Annan hablaba de "reinventar las Naciones Unidas", y con ello de reinventar los Estados. "La globalización es muy beneficiosa para algunos y es potencialmente beneficiosa para todos, pero sólo si los Estados trabajan conjuntamente para que estos beneficios alcancen a todo su pueblo. En contraste, miles de millones quedarán abandonados a la pobre7a y otros países emergentes están a la merced de súbilos cambios económicos. Creemos que la tarea fundamental a que nos enfrentamos es conseguir que la mundialización se convierta en una luerza positiva para todos los habilantes del mundo, ya que si bien ofrece grandes posibilidades, en la aclualidad sus bencficios se distribuyen en forma muy desigual, al igual que sus cosios. Por eso consideramos que sólo desplegando esfuerzos amplios y sostenidos para crear un futuro común, basado en nuestra común humanidad, en loda su diversidad, se podrá lograr que la mundialización sea plenamente incluyente y equitativa"

El discurso de Kofi Annan se silúa en la línea de gobernar la globalización. “Los problemas mundiales deben abordarse de manera tal que los costos y las cargas se distribuyan con justicia, conforme a los principios fundamentales de la equidad y de la justicia social. Los que sufren o los que menos se benefician merecen la ayuda de los más beneficiados. Til logro de esos objelivos (desarrollo y erradicación de la pobreza) dependen, entre otras cosas, de la buena gestion de los asuntos públicos en cada país. Depende lambién de la buena gestión de los asuntos públicos en el plano internacional y de la transparencia de los sistemas financieros, monclarios, comerciales. Propugnamos un sistema comercial y financiero multilateral abierto, equitativo, basado en normas, previsible y no discriminatorio. Pedimos a los países industrializados que adoplen una política de acceso libre de derechos y cupos respece de virlualmente todas las exporlaciones de los paises menos avanzados... Oue concedan una asistencia para el desarrollo más generosia, especialmente a los países que se estain esforzando genuinamente por destinar sus recursos a reducir la pobreza"... I o que Kofi Annan solicita a nivel mundial vale para lograr la equidad y justicia social a nivel nacional.

Sólo un testimonio más, desde un autor que conoce como pocos las entrañas del mercado mundial, George Soros: "Los gobiernos de Thalcher y Reagan co- 
menzaron a reducir el papel del Estado en la economía. Su consecuencia fue que los impuestos sobre el capital descenclicron, mientras que los impucstos sobre el trabajo han seguido creciendo". Como ascgura el economista internacional Dani Rodrik, "la globalización aumenta las demandas al Estado de proporcionar una seguridad social, al liempo que reduce su capacidad para hacerlo. Esto lleva en sí el germen de conflictos sociales. Si los servicios sociales se recorlan en exceso, al tiempo que aumenta la inestabilidad, la insatisfacción popular podría desatar oleadas de proteccionismo, especialmente si la expansión actual va seguida de una recesión de cierla gravedad. Essto podria conducir a un colapso como el de los años treinta. Esio me lleva al problema más conluso: el de los valores y la cohesión social. Toda sociedad necesita valores comparliclos. Los valores del mercado no sirven para este propósito, porcjue sólo reflejan lo que un participante en el mercado está dispuesto a pagar a otro dentro de un libre intercambio. Los mercados reducen lodo, incluidos los seres humanos y la naluraleza, a mercancía. Podemos lener una economia de mercalo, pero no podemos tener una sociedad de mercado. Además de los mercados, la sociedad necesila instituciones que sirvan a lines sociales como la libertad política y la justicia social. Isstas instituciones existen en países concretos, pero no en la sociedad glohal. İl desalrrollo de una sociedad global se ha (juedado retrasada respecto al de una economia global. $\wedge$ menos que se acale con esta distancia, el capitalismo global no sobreviviri”". (Г:(А; 1988; рГ.8()()-()()())

He tratado de recoger en un reciente articulo las críticas (jue el neoliberalismo ha formulado contra las politicas keynesianas y el fistado social de hienestar, asi como las reflexiones y las criticas que se repiten en las cumbres mundiales contra la presente glohalización, en sus disemelrías económicas y desigualdades

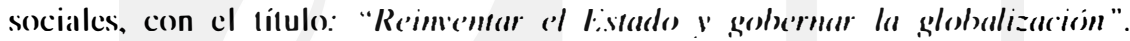
(Realidad, $\mathrm{N}^{\circ}$ 82) Desconocemos en este momento qué resultados o medidas politicas puedan derivarse del diálogo $\Lambda$ NI:P-( $;() \mid: S$, interrumpido bruscamente por los alaques terroristas en los listados Unidos, que han venido a profundizar aún más la crisis mundial y el pánico polarizante. Iintre las 250 medidas o propuestas de la $\Lambda$ NI:P, hay muchos aportes valiosos. Sin embargo, seria necesario abrir este diálogo a los sectores lahorales y seria necesario (que el secer empresarial se ahra a un anailisis mis objetivo de la globalizacion. en sus aspectos positivos y en sus consecuencias excluyentes, que termine en una revision sincera de sus principios doctrinarios si realmente queremos "un nuevo lil Salvador con el compromiso de todos".

ENADE-2001: ¿Un compromiso de todos? 